\title{
Una máquina cuyo combustible es el aburrimiento y la monotonía
}

A machine whose fuel is boredom and monotony

Martin De Mauro Rucovsky CONICET Universidad Nacional de Córdoba Argentina 
En lo siguiente proponemos una relectura de La condition ouvrière de Simone Weil, texto clásico de denuncia vinculado a la literatura marxista, obrera y sindical, pero a partir del denominado giro afectivo en las ciencias sociales. Planteamos un análisis que enfoca aspectos poco atendidos en el análisis de esta (Cabaud, 1957; Bea, 2010; Pétrement, 1973; Andrés García, 2016; Chenavier, 2016 y McLellan, 1989), proponemos detenernos en aquellos afectos, sentimientos y regímenes de lo anímico que se miden en la experiencia de personificación de Weil, durante su trabajo como obrera en los primeros años de la década del treinta en distintas fábricas francesas. En este sentido, el registro afectivo de Weil vinculado estrechamente al mundo obrero y la sensibilidad industrial fordista se lee, por contrapunto, a la instalación de una agenda anímica neoliberal vinculado a los regímenes normativos del optimismo y el entusiasmo, atmósferas afectivas de baja modulación y tedio, o la circulación anímica de la felicidad y sus promesas de apego emocional (Ahmed, 2019).

Palabras-clave: fordismo; afectos; estudios culturales; Simone Weil

\section{Abstract}

In the following we propose a rereading of La condition ouvrière by Simone Weil, classic text of denunciation linked to Marxist, worker and union literature, but from the socalled affective turn in the social sciences. We propose an analysis that focuses on aspects few attended in the analysis of this work (Cabaud, 1957; Bea, 2010; Pétrement, 1973; Andrés García, 2016; Chenavier, 2016 y McLellan, 1989), we propose to stop at those affections, feelings and mood regimes that are measured in Weil's experience of personification, during her work as a worker in the early 1930s in various French factories. In this sense, Weil's affective register closely linked to the working-class world and Fordist industrial sensibility reads, by counterpoint, to the installation of a neoliberal psychic agenda linked to the normative regimes of optimism and enthusiasm, low modulation and boredom affective atmospheres, or the mental circulation of happiness and its promises of emotional attachment.

Keywords: fordism, affects; cultural studies; Simone Weil 
En lo siguiente proponemos una relectura de La condition onvrière de Simone Weil, texto clásico de denuncia vinculado a la literatura marxista, obrera y sindical, pero a partir del denominado giro afectivo en las ciencias sociales. Planteamos un análisis que enfoca aspectos poco atendidos en el análisis de esta obra Cabaud, 1957; Bea, 2010; Pétrement, 1973; Andrés García, 2016; Chenavier, 2016 y McLellan, 1989), proponemos detenernos en aquellos afectos, sentimientos y regímenes de lo anímico que se miden en la experiencia de personificación de Weil, durante su trabajo como obrera en los primeros años de la década del treinta en distintas fábricas francesas.

La condition ouvrière registra un conjunto de experiencias obreras y fabriles que son, en principios ajenas y externas a la autora del texto: Simone Weil como profesora universitaria comprometida con la causa obrera y el marxismo. Texto de análisis y de denuncia, escrito desde las marcas corporales o desde la personificación de una condición subyugada, La condition omvrière supone (como subtexto) un habla subalterna que quiere ser recuperada, pero supone asimismo un cierto registro de lo anímico y lo afectivo subalterno. En efecto, proponemos leer a Simone Weil, no sólo a partir de la pregunta de G. Spivak (2011) ¿puede hablar el subalterno?, sino también evidenciando un punto de cruce y mixtura entre los estudios sobre afectos, las emociones y la pregunta de Spivak, ¿se puede sentir ya no por otro sino como otro? El análisis de Weil, pareciera indicar una respuesta afirmativa, como si en su escritura se construyera un tipo de sensibilidad obrera diferida, un conjunto de afectos desligados y mediados por un sujeto (este sujeto es, de nuevo, la misma Simone Weil). Tal como fue observado, en el centro de la máquina filosófica, la emoción pareciera ser equivalente a una vivencia originaria o una experiencia realista, es decir, en el análisis de Weil se puede constatar una escala anímica que se corresponde miméticamente (o en la personificaciónidentificación de la vida de un otro obrero subalterno) con un conjunto de afecciones corporales, como si La condition ouvrière fuera un taller afectivo, una clase de dolor, agotamiento y aburrimiento registrado en forma de diario filosófico. Y aquí la pregunta es tan simple como pertinente, ¿la emoción y afectividad obrera necesita de la emoción empírica y psicológica para estar cargada de veracidad? La escritura de Weil, parece demandar cierto punto de identificación entre experiencias (la propia con la ajena, la filosófica-académica con la obrera y subalterna) pero no obstante, y este es el punto 
productivo que vamos a explorar, esto implica un "conocimiento experimental" que parte de la singularidad del cuerpo femenino, un modo de sentir determinado, un desgaste y cansancio anímico, unas emociones que faltan o que no adquieren la suficiente relevancia en el análisis estrictamente ideológico, racional (logocéntrico) y de toma de conciencia.

\section{Una fábrica es un lugar en el cual uno choca duramente, dolorosamente}

En el año 1951 se publica La condition ouvrière (Gallimard, París) que registra la experiencia de Simone Weil, en la fábrica Renault, durante diciembre de 1934 y agosto de 1935. Weil, dedica su año sabático de enseñanza en el lycées de señoritas de Le Puy como cortadora (obrera en las prensas) en la usina de fabricación eléctrica Alsthom en París, luego empleada como embaladora en los establecimientos J.-J. Camaud et Forges de Basse-Indre en Boulogne-Billancourt y finalmente, como fresadora entra en las fábricas Renault en Boulogne Billancourt, Luchaire Saint-Ouen, Langlois Ménilmontant, Salmson, Caudron, Gévelot. La tarea de Weil es, en este sentido, la de un trabajador manual estándar, pero al mismo tiempo su especificidad radica en que forma parte del grupo más oprimido de la sociedad industrial-taylorista de entreguerras- las mujeres trabajadoras no calificadas, y ese es su punto de partida. Aunque no se trata de una obra editada por la autora, al igual que la totalidad de sus textos, se conserva la recopilación temática a partir del trabajo de Albert Camus y del fondo bibliográfico de la Biblioteca Nacional de Francia. Sus anotaciones sobre la fábrica recogen trozos y reflexiones de gran sutileza y realismo sobre las piezas que ha de taladrar, las chapas que ha de cortar, o los cartones que ha de troquelar acompañadas en ocasiones de los menudos incidentes del trabajo: las piezas estropeadas, las peleas de los encargados y jefes y las pésimas condiciones del trabajo- el metal frío, el ruido de las máquinas, la temperatura helada de los vestuarios. Compuesta de cartas, tratados, ensayos, fragmentos, conjuntos de anotaciones y apuntes taquigráficos, La condition ouvrière es un diario de fábrica y de investigación militante que pretende hacer memoria del sufrimiento obrero. ${ }^{2}$

El texto de Simone Weil (1909-1943) se propone describir la experiencia cotidiana y en primera persona, a nivel del cuerpo, los afectos y sentimientos que le suscita, una condición social y una figura ontológica que es la obrera-proletaria. Clase

1 TOMMASI, Wanda. "Cosmos: la experiencia del cuerpo femenino en Simone Weil”, 1993, p. 101.

2 Después de su año de fábrica, Simone Weil partió con sus padres a España y Portugal, desde el 25 de Agosto hasta el 22 de Septiembre de 1935, lo que marca otro tono en su reflexión filosófica ligada a la espiritualidad del trabajo y el cristianismo. 
social descrita, por definición, en la capacidad de trabajo, creación y de entendimiento en acción. Con el diario de fábrica Weil, se propone vivir la realidad de los oprimidos no solamente al lado de ellos o próximos a ellos (como ellos) sino en el corazón del taller, entre ellos y en los engranajes de la fábrica (sentir como ellos). Así, la relación que se establece entre la sujeta autoral y los otros del relato supone una orientación: los otros están descritos desde la proximidad de "al lado" y desde una inclinación o posición de adyacencia.

La condition ouvrière trata de la renuncia (parcial y delimitada) de su posición o más bien de la recitación de un código de viejas reminiscencias franciscanas ${ }^{3}$ : "vocación de entrega, humildad y despojo material, de abdicación de todo derecho y necesidad y finalmente de retiro a una vida de pobreza (paupertas) o en este caso de retiro hacia una vida obrera-proletaria" o como escribe su colega Albertine Thévenon " deseo de hacerse carne con los desdichados".

La condition ouvrière enuncia un pacto de ponerse deliberadamente en el punto de vista de los de abajo. Este pacto registra, a través de la experimentación y su anotación (epistolar, de intervención y luego ensayístico), una forma de vida obrera que Weil reconstruye en el contacto directo y de primera mano, como modo de aproximación a una realidad, a una política de la verdad, "este es el contacto con la vida real" escribe 5 . Contacto directo entonces, que no olvida las distancias y privilegios (de origen) que le son constitutivos a su mirada, lo que es decir, una mirada de extranjera e invitada que no deja de registrar con dedicado afán. En este sentido el texto de Weil, no es una anotación con pretensiones antropológicas en donde se indican taxonomías más o menos minuciosas y detalladas, o que se experimenta con la intención de proletarizarse:

\footnotetext{
Me sería fácil no llegar a sentirlo si hubiese hecho esta experiencia únicamente como un simple juego, como un explorador que va a vivir en poblados lejanos, pero sin olvidar jamás que es un extranjero. Por el contrario, yo alejaba sistemáticamente todo cuanto pudiera recordarme que se trataba de una simple experiencia. ${ }^{6}$
}

Antes que un explorador que va a experimentar la extranjería, pero precavido de su condición, suerte de método etnográfico que pretender salvar las distancias y los privilegios declarados, el texto de Weil, trata más bien de un diario como intervención crítica y política sobre una "cuestión social" que procede a través del descenso social

3 AGAMBEN, Giorgio. Altísima pobreza. Reglas monásticas y forma de vida, 2013, p.155-204.

4 WEIL, Simone. La condición obrera, 2010 p. 272.

5 Idem. La condición obrera, 1962, p. 27.

6 Idem. La condición obrera, 2010, p. 76. 
en vistas de una mayor comprensión porque desde "arriba se está en mala posición para darse cuenta de las cosas"7. O como decíamos, la experiencia de Weil, se lee en términos de una política de la verdad sobre un modo de vida obrero configurado en el dolor, el sufrimiento, la desigualdad y la injusticia.

Pero la fábrica es también un condensador de afectos y sentimientos: "ya estés irritado, triste o disgustado, trágate (...)Y lo mismo ocurre con la alegría"8. Introducir esta dimensión problemática de las emociones obliga a desplazar el registro de lo racional (logos) o lo argumentativo, la toma de conciencia mental o de una facultad cognitiva en vistas de una mayor relevancia de lo epidérmico, la vibración sensible y anímica que se despliega en el terreno de lo corporal. Se trata de las capacidades corporales de afectar y ser afectados, o el aumento y la disminución de la capacidad del cuerpo para actuar, para comprometerse o conectarse. Ese tipo de registro de lo anímico, que cualifica y moldea un tipo de vida obrera, ilumina un territorio clave para pensar la instauración y consolidación de una sensibilidad ligada al fordismo y la experiencia proletaria. En este sentido, la cita que intitula este apartado - “una fábrica es un lugar en el cual uno choca duramente, dolorosamente"-, extraída de la carta dirigida a su amiga, sindicalista y profesora Albertine Thévenon (1905-1993) así se completa: "Una fábrica es un lugar en el cual uno choca duramente, dolorosamente; pero a pesar de todo con alegría, con la vida de verdad". Y pareciera que ese sentimiento de alegría se vinculada directamente con la verdad, con el acceso a esa experiencia y sensibilidad obrera.

\section{El combustible anímico de la fábrica}

Lo que nos interesa, pues, no es tanto la pregunta ontológica y epistemológica sobre ¿qué son los afectos (affect), las emociones (emotion), impresiones o sentimientos (feeling), el temple de ánimo o los ambientes (stimmung) o de qué están hechos? ¿qué significan? ¿cómo distinguirlos y cómo diferenciarlos? ${ }^{10}$ sino más bien, ¿cómo

7 Ibidem, p. 78.

8 Idem. La condición obrera, 1962, p. 23.

9 Ibidem, p. 20.

10 La distinción analítica entre emociones y afectos es, para Sara Ahmed, una reinstalación de la falacia opositiva entre naturaleza/cultura porque ignora el carácter sobredeterminado de los procesos corporales. No obstante, para otras posiciones y autores (Massumi y Flatey por ejemplo) esta distinción si es productiva: las emociones conforman un sistema comunicativo integrado por elementos expresivos, gestuales, lingüísticos, fisiológicos, conductuales y cognitivos marcados por la intersección de múltiples variables sociales (género, sexualiudad, raza, clase, etc) y condiciones espacio temporales. El régimen de afectividad supone, en otro orden analítico, un sistema comunicativo (desestructurado, no coherente y no lingüístico) como intensificación del cuerpo pero con una inscripción cultural mucho más difusa (AHMED, Sara. La política cultural de las emociones, 2015, p. 9-18; MACON \& SOLANA, Pretérito indefinido. 2015, p.19). 
funcionan y que hacen?, ¿de qué modo circulan y producen efectos, sus modos de conjugación y declinaciones posibles?, ¿cuáles son sus condiciones de producción, circuitos de distribución y las situaciones para su recepción?, ¿cómo logran apegos y adherencias múltiples en cuanto sensorium histórico del momento fordista?. O en otros términos ¿cómo logran matrizar lo sensitivo y lo emocional a nivel de los cuerpos y las vibraciones corporales? En este marco, los afectos son sociales y relacionales, pero no estados psicológicos, sino prácticas sociales y culturales capaces de constituirse, a la vez, en articuladores de experiencia. Estas líneas de indagación son algunas de las marcaciones que atraviesan muchos de los recorridos críticos recientes en torno al giro afectivo en ciencias sociales (MUÑOZ, Cruising Utopia, 1999; SEDGWICK, Touching Feeling, 2003; CVETKOVICH, An archive of feelings, 2003; MACÓN \& SOLANA, Pretérito indefinido, 2015; DHABAR \& MATTIO, "Es lo que siento" 2020), pero su lugar implica considerar las tonalidades afectivas singulares.

Simone Weil, plantea la necesidad de comprender las causas de la opresión social, no tanto como un ejercicio del entendimiento- que por medio de categorías se aproxima a la realidad, tampoco como una explicación racional sobre un acontecimiento, sino para comprender que estaría en juego en una relación directa con la experiencia sensible. Para Weil, sería justamente habitar el trabajo manual, tal y como lo viven en su propia materialidad y cotidianidad los obreros de la época, lo que abriría la puerta a la posibilidad de comprender las causas de la opresión social. Se trata, entonces, de la corroboración de una realidad no develada, enmascarada, poco conocida o encubierta por la imaginación, la ilusión o las abstracciones teóricas (que identifica con su oficio teórico académico), por contrario, la verdad y la alegría en realidad no es otra que "las condiciones reales que determinan la esclavitud o la libertad para los obreros" ".

A través de una perspectiva sindicalista, militante y heterodoxamente marxista, la pensadora francesa descubre la organización de la empresa, su funcionamiento interno en el corazón del mecanismo fabril, esto es, la división de tareas (en la fragmentariedad del trabajo que recae en una única pieza), la jerarquía autoritaria e igualmente arbitraria, el progreso de la racionalización "maquínica", la opresión burocrática y el trabajo especializado.

La descripción de Weil, hace foco en la fábrica moderna, las afecciones del apuro, de una temporalidad acelerada, vertiginosa y cíclica. Fábrica moderna que la prosa de K. Marx, caracterizó desde lo visual y lo táctil como "un monstruo autómata compuesto de numerosos órganos mecánicos e intelectuales- máquinas y obrerosque obran de concierto y sin interrupción, para producir un mismo objeto, estando

11 WEIL, Simone. La condición obrera, 2010 p. 46. 
subordinados todos esos órganos a un poder motor que se mueve por sí mismo" "12. Ahí donde la máquina parece haber inventado los nervios modernos -"el trabajo maquinizado agrede intensamente el sistema nervioso" 13 y la monstruosidad propia del motor automatizado - "el sistema de la maquinaria, pues la máquina automática no es más que la forma más acabada y más adecuada de la misma, con la que la maquinaria se convierte en sistema" 14 es cuando la fábrica aparece, en la escritura de Weil, imbuida de sentimientos y valores afectivos que tenemos sobre las cosas y los lugares: los itinerarios que recorrimos, las cosas que nos pasan o la gente con la que nos cruzamos. ${ }^{15}$ En efecto, “¿se imaginan una máquina cuyo combustible sea la ansiedad, el aburrimiento o el cansancio?" ${ }^{\prime 6}$. Aquello que circula por la cinta transportadora, en el ensamblaje mecánico-intelectual y social que es la fábrica, son objetos de acumulación de valor, mercancías, afectos y apegos. La fábrica es, entonces, un mecanismo condensador de sentidos que funciona sobre la base de una economía de intercambio de mercancías, de flujos de compra-venta pero, también en cuanto economía afectiva ${ }^{17}$. Es decir, en La condition ouvrière se trata del tráfico emocional que regula la relación con el entorno industrial, y en donde está en juego "un modelo de sociabilidad emotiva que se sobrepone a las determinaciones del análisis individual y las generalizaciones superestructurales" ${ }^{\prime 18}$.

Producto de la disciplina biopolítica y la lógica taylorista en su evocación de los principios cartesianos, el control de los movimientos corporales y sus funciones productivas, pero también sobre los afectos y las emociones, la maquinaria industria

12 MARX, Karl. El capital. Tomo I, 1995, p.381.

13 Ibidem, p.422.

14 Idem. "Fragmento sobre las máquinas", 1985, p.105

15 Las emociones y sentimientos son relacionales porque involucran diferentes movimientos -de orientación, vinculación, proximidad o distanciamiento- de otras personas, de tal manera que definen los contornos, ese es su efecto de frontera y de superficie, del espacio social y corporal (Ahmed, 2015:30). Efectivamente, según detallamos previamente, la relación que se establece entre la escritura de Simone Weil y sus compañeros de trabajo supone una orientación de proximidad y adyacencia.

16 MOSCARDI, Matías. La rosca profunda, 2016, p.16

17 Estrictamente los afectos-emociones no residen en los objetos sino que son efectos de su circulación y contacto (del latín emovere, la palabra emoción hace referencia a mover o moverse). Insertos en una economía de acumulación de valor (en sintonía con la teoría marxista de la circulación de la mercancía), la economía afectiva supone una crítica a los modelos psicológicos de interiorización que hacen de las emociones propiedades que tienen los sujetos para pensarse en procesos insertos en una amplia red de actores humanos y no humanos. La atribución de propiedades a los objetos supone que las emociones y los afectos funcionan para moldear lo que los cuerpos pueden hacer pero funcionan también moldeando las superficies de los cuerpos individuales y colectivos que toman forma a través de la repetición de acciones a lo largo del tiempo. Así, el trabajo de la emocionalidad y afectividad involucra que ciertos signos queden "pegados" a ciertos cuerpos y objetos (AHMED, Sara. La política cultural de las emociones, 2015, p.19-45).

18 CUELLO, Nicolás. "Presentación: el futuro es desilusión”, 2019, p. 14. 
impone ritmos de aceleramiento, repetición y rapidez que hacen a esta clase social: la "descomposición de cada trabajo en movimientos elementales que se reproducen en trabajos muy diferentes, de acuerdo con diversas combinaciones". ${ }^{19}$ El control biopolítico del tiempo y su cadencia productiva, continuamente a disposición de los jefes, es una mezcla de uniformidad y de azares, según los incidentes y las órdenes recibidas. La racionalización de la fuerza humana del trabajo es, a propósito de la coincidente inspiración disciplinar-taylorista, el control del ritmo y del tiempo cuyos efectos son tanto más perversos cuanto empuja al obrero, por vía del salario por pieza, a aumentar la cadencia productiva. En este sentido, la monotonía y el aburrimiento obrero es la emoción preponderante, ligada directamente a la cadena de obediencia disciplinar y a la limitación del manejo en la disposición del tiempo, es decir, el orden en el cual el obrero lleva a cabo su propio trabajo que se ve agravado, desde luego, por la monotonía rítmica de la tarea. De allí que la servidumbre, insiste Weil, se halla en el curso mismo del trabajo, en la regularidad monótona de su cadencia temporal y en el tiempo reiterativo desde la cual se proyecta un promedio de rendimiento que hace a la eficacia económica de la fábrica.

Desde esta perspectiva Simone Weil, insiste en una nueva forma de opresión y de lucha de clases, no formulada por Marx y que tiene que ver con un sistema de producción en el que el trabajo se halla subordinado por intermedio de la máquina a la función de coordinación de tareas. Todo lo que es propiamente temporal es confiado al objeto (mercancía, afectos y apegos) y todo aquello que corresponde a la pura repetición de un gesto idéntico es confiado al hombre. Simone Weil, se pregunta por las condiciones materiales de opresión de su época y que le permite comprender que los ruidos, los gestos, las miradas y las manifestaciones de la condición obrera, hacen parte de una interpretación en un sentido amplio de opresión que ella estaría proponiendo en oposición al socialismo científico de su época.

En este contexto, de un escepticismo singular y en el paisaje social que reconstruye la pensadora francesa, la condición obrera es, entonces, un modo de vida subyugado y dócil, marcada fuertemente por la esclavitud de sus vínculos y por la humillación ante la máquina industrial, una obediencia generalizada, o como anota

19WEIL, Simone. La condición obrera, 2010 p. 30. Y aquí podemos notar la influencia de los estudios sobre refracción, perspectiva, la geometría analítica y de la naturaleza de la luz que pueden rastrearse hasta La dioptrique (1637) de Renee Descartes en la disciplina biopolítica, específicamente, la organización espacial del panóptico. El panoptismo es, vale recordar los estudios canónicos de Michel Foucault (Surveiller et Punir de 1975), un tipo de organización espacial, una arquitectura proyectada en torno a un punto central desde el cual sería posible verlo todo permanentemente (el “ojo del poder” es su símbolo) sin la intervención de un sujeto individual o un soberano. 
"una docilidad de bestia de tiro resignada" 20 . La fábrica es, en el texto de Weil, un dispositivo deshumanizante que gira en torno a los cuerpos y la sobreexplotación. Y allí se descubre una paradoja en el planteo de Weil: puesto que el trabajo es una figura de humanización y además funciona como proyecto civilizatorio a construir, no obstante, en el caso de la fábrica Renault y sus condiciones específicas, el trabajo es un umbral de pérdida de toda dignidad que arroja a los obreros a los bordes de la especie y de lo propiamente humano, valga la insistencia, "condición de bestia de carga" y de "seres tratados como desecho"21. E inclusive, vale agregar, la compensación e incremento salarial contribuye a tornar todavía más humillantes las condiciones del trabajo, a exigir mayor productividad y a rebajar la situación moral-espiritual de los obreros.

Así, sus impresiones en los talleres fabriles de Renault están motivadas también por la búsqueda de un ethos sindical, algún tipo de gesto de solidaridad y camaradería entre pares. Pero el diario de fabrica tampoco registra estos lazos afectivos o algún atisbo de emoción ligada a la hermandad, la amistad o la fraternidad (del lat. fraternittas, -ātis). Las impresiones de simpatía y compañerismo se encuentran en microgestos, manifestados silenciosamente en miradas o en una sonrisa cómplice; no obstante, la indiferencia del peón especializado es más frecuente porque este no tiene otros estimulantes más que el miedo, el salario y el dinero.

\section{Afectos obreros y corporalidad femenina}

Yo era la pobre obrera trabajando en la fábrica con la pena en los ojos $y$ con las manos ásperas

José María Fernández Unsain en Ayer y Hoy: el día de una obrera de Hugo del Carril (1951)

Los afectos y emociones de la condición obrera pasan, necesariamente, por el cuerpo fatigado y sufriente de Weil, sus lágrimas, la rabia impotente, el miedo, las "broncas", la necesidad de dormir, la extinción de la facultad de pensar. Y ese registro crítico se funda, principalmente, en una fenomenología obrera que vincula el cansancio corporal extremo y la captura de toda vitalidad con la resignación ética-política, o, en otros términos, la fatiga y el sufrimiento con el "embrutecimiento", la humillación, la esclavitud y la falta de pensamiento, de dignidad o, la incapacidad de contestación y de resistencia. Agotamiento físico-corporal y resignación moral que hacen a un afecto de infelicidad que es propio de la condición obrera pero, también de un estado de ánimo

20 Idem. La condición obrera, 1962, p. 22.

21 Idem. La condición obrera, 2010, p. 76 y 270. 
generalizable, de las condiciones bajo las cuales existe la humanidad: "El hecho de ser arrancado de la condición humana, en la fábrica, deriva de esta forma de maquinismo en que el obrero se ve reducido a ejecutar series, sin estar nunca en posición de coordinar la secuencia de las operaciones, secuencia pensada por un ingeniero y cristalizada en las máquinas" ${ }^{22}$.

De este modo, Weil encuentra que esos sentimientos de agotamiento e infelicidad no son algo arbitrario (o deberíamos decir, no responden a la subjetividad psicologizante) sino que están asociados a circunstancias específicas y precisamente por ello, tales sentimientos pueden modificarse mediante una transformación radical de las circunstancias. De allí que afectos y sentimientos de la condición obrera y por generalidad de la humanidad, vividos como propios y registrados como ajenos también, se vinculan en una misma trama inmanentemente política. El cuerpo fatigado de Weil, funciona entonces, como campo de auto-experimentación biopolítica en donde afectos, sentimientos y resistencia política se anudan en torno a la causa obrera.

En este sentido, el registro afectivo de Weil, vinculado estrechamente al mundo obrero y la sensibilidad industrial fordista se lee, por contrapunto, a la instalación de una agenda anímica neoliberal que promueve versiones higiénicas de las vidas psíquicoafectivas en común que institucionalizan el individualismo de mercado, los regímenes normativos del optimismo y el entusiasmo- vinculados a principios del nuevo management, del public choice, la autoayuda, el coaching y también del mindfulness- ${ }^{23}$ atmósferas anímicas de baja modulación y tedio ${ }^{24}$, protocolos estético-coloniales y lazos sociales mediados por el comportamiento securitista.$^{25}$

Así, la vibración del cuerpo y los sentimientos que lo orientan producen un conjunto de modulaciones que, leídos a la luz de la gramática cultural de las emociones (Ahmed, 2017) caracterizan a La condition ouvrière por una oscilación entre la alegría descripta y la humillación deliberada, la monotonía y el aburrimiento, el desgano, la fatiga corporal y la indiferencia generalizada. Y de esa textura de sentimientos en el registro anímico de Weil, sobresale uno en particular, el sentimiento de inferioridad asociado a la subordinación y la obediencia pasiva:

porque una sola palabra lo puede echar afuera, y cualquier día una desafortunada querella puede traer consigo esa palabra. Siempre gravita sobre la cabeza del obrero en el astillero y en la fábrica no solamente el riesgo

22 CHENAVIER, Roberto. "Introducción”, 2010, p. 20.

23 DE MAURO RUCOVSKY, Martín. "Rotar en la precariedad o sobre el trabajo de los jóvenes", 2019a.

24 Idem. "Taedium Vitae: Precarity and affects in porteña night", 2019b.

25 CUELLO, Nicolás. "Presentación: el futuro es desilusión”, 2019 p.15. 
de una falta ocasional, no solamente el riesgo que acarrearía una acción militante, si está decidido a emprenderla, sino también el riesgo de desagradar. $^{26}$

Inferioridad que se liga así a la pérdida de "dignidad del ser humano" (del lat. dignitas, -ätis. que refiere tanto a una cualidad como a un cargo, empleo, posición y un oficio) y la desigualdad en la relación de fuerzas, las presiones cotidianas de la pobreza y la necesidad, el aburrimiento ligado a la monotonía de la tarea y finalmente la dependencia de los mandos obreros ante superiores o contramaestres.

De este modo, el diario de Simone Weil, permite leer una dimensión afectiva del trabajo vinculado al auge de la gran industria taylorista en el contexto anglo europeo, la intensificación de la explotación laboral y la opresión social, la consolidación de los estados nacionales y el liberalismo modernizante de entreguerras en cuyo centro la figura de la trabajadora femenina (des)calificada adquiere una intensidad creciente: “yo, en mi calidad de obrera, estaba en una situación doblemente inferior, expuesta a sentir mi dignidad herida no sólo por los jefes, sino también por los obreros en tanto que soy mujer" ${ }^{27}$. Contemporánea al feminismo de la segunda ola, las sufragistas, el feminismo marxista de Rosa Luxemburg y más aún el anarcofeminismo de principio de siglo, ${ }^{28}$ Weil, advierte la captura de las mujeres cis como trabajo no calificado producto de la dinámica taylorista y su mecánica interna (tendencia al aumento incesante de la producción sin mayores innovaciones técnicas). Pero más aún, la explotación del trabajo femenino y del trabajo femenino generizado se inscribe en la economía política

26 WEIL, Simone. La condición obrera, 2010, p. 235.

27 Ibidem, p.92.

28 El nominativo "segunda ola del feminismo" es una categoria utilizada en la teoría y la historia feminista para aglutinar a un conjunto basto de posturas, activistas y pensadoras feministas dentro del eje euronorteamericano. Dicha categorización tiende a ubicar, entre comienzos y mediados del siglo XIX, al movimiento sufragista (derecho al voto o sufragio universal y a la educación o al libre acceso a los estudios superiores) entre sus principales objetivos políticos. Sin embargo, la agenda social y política de la segunda ola suele exceder el marco liberal igualitarista (ref. Harriet Taylor y John Stuart Mill) e incluir también la lucha antiesclavista y antirracista (ref. Sojourner Truth), la perspectiva feminista al interior del movimiento obrero organizado (marxista, socialista y anarquista), la división sexual del trabajo (igualdad salarial y equiparación de sueldos, jornadas y el ejercicio profesional) y las distintas reivindicaciones por derechos civiles, la patria potestad de hijos y por administrar sus propios bienes. Cfr. ÁLVAREZ, Ana de Miguel; AMORÓS, Celia Puente. Teoría feminista Vol. 1: de la Ilustración a la globalización, 2005 y BELTRÁN, Elena; MAQUIEIRA, Virginia; ÁLVAREZ, SILVINA Y SÁNCHEZ, Cristina Feminismos Debates teóricos contemporáneos, 2008. 
del género, ${ }^{29}$ las jerarquías entre obreros (especializados o peones) y la feminización del trabajo en su tarea de reproducción de la vida.

\section{Referências Bibliográficas}

AGAMBEN, Giorgio. Altísima pobreza. Reglas monásticas y forma de vida.Traducción: Flavia Costa y María Teresa D’ Meza. Buenos Aires: Adriana Hidalgo, 2013.

AHMED, Sara. La promesa de la felicidad. Una crítica cultural al imperativo de la alegría. Traducción: Hugo Salas. Buenos Aires: Caja negra, 2019a.

AHMED, Sara. Fenomenología queer. Orientaciones, objetos, otros. Traducción: Javier Sáez. Madrid: Bellaterra, 2019b.

AHMED, Sara. La politica cultural de las emociones. México: UNAM, Programa Universitario de estudios de género, 2015.

ÁLVAREZ, Ana de Miguel; AMORÓS, Celia Puente (coord.). Teoría feminista Vol. 1: de la Ilustración a la globalización. Madrid: Minerva, 2005.

BEA, Emilia. Simone Weil. La conciencia del dolor y de la belleza. Madrid: Trotta, 2010.

BELTRÁN, Elena; MAQUIEIRA, Virginia; ÁLVAREZ, SILVINA Y SÁNCHEZ, Cristina (eds.). Feminismos Debates teóricos contemporáneos. Madrid: Alianza, 2008.

CABAUD, Jacques. L’Expérience vécue de Simone Weil. París: Librairie Plon, 1957.

CHENAVIER, Roberto. "Los caminos de la recepción de la obra de Simone Weil. Algunos hitos". Ápeiron. Estudios de filosofia - Simone Weil: pensar con un acento nuevo. n.5, out. 2016. Disponible en: https://s3.amazonaws.com/wix-anyfile/2DpKQbovQXuErNfqVAVD Los $\% 20$ caminos $\% 20$ de $\% 201 \mathrm{a} \% 20$ recepci $\%$ C $3 \%$ B 3n $\% 20$ de $\% 201 \mathrm{a} \% 20 \mathrm{obra}^{2} \% 20 \mathrm{de} \% 20$ Simone \%20Weil \%20-\%20Algunos\%20hitos.pdf Acceso en: 28 jun. 2019.

CHENAVIER, Roberto. "Introducción”. In: La condición obrera de Simone Weil. Buenos Aires:

29 Desde los análisis de la economía se insiste en la pregunta sobre cómo se reproducen las sociedades y sobre la sostenibilidad de la vida. En efecto, estos análisis cuestionan las corrientes de economía hegemónicas (incluyendo posturas marxistas) porque no consideran la reciprocidad entre los mercados financieros globales-nacionales y los flujos monetarios (macroeconomía) en relación a la administración doméstica, la gestión del cuidado y el afecto, la alimentación y el acceso a recursos cotidianos (microeconomía o esfera económica invisibilizada); E incluso más, esta mirada ortodoxa (cuyo paradigma es la economía neoclásica) desatiende al heteropatriarcado como nivel de análisis en tanto organizador de la economía, ni tampoco logran dar cuenta de los procesos vitales, los trabajos no remunerados, el hogar y el ámbito de lo privado-doméstico (PÉREZ OROZCO, Amaia. Subversión feminista de la economía, 2014). 
Cuenco de plata, 2010.

CUELLO, Nicolás. "Presentación: el futuro es desilusión". In: AHMED, Sara. La promesa de la felicidad. Una crítica cultural al imperativo de la alegría. Buenos Aires: Caja negra, 2019a.

CVETKOVICH, Ann. An Archive of Feelings. Trauma, Sexuality, and Lesbian Public Cultures. Durham: Duke, 2003.

DHABAR, Victoria; MATTIO, Eduardo. "Es lo que siento": el lugar de los afectos en la conversación feminista". Revista Heterotopías, vol. 3 n. 5, 2020: "Giro afectivo y discursos sociales: críticas, representaciones y políticas". Disponible en: https://revistas.unc.edu.ar/index.php/ heterotopias/article/view/29032 Acceso en: 25 jul. 2020.

DE MAURO RUCOVSKY, Martín. (2019a) "Rotar en la precariedad o sobre el trabajo de los jóvenes". En A Contracorriente. Una revista de estudios latinoamericanos. NC State University, vol. 16, n. 3 (Spring 2019): 139-160. Disponible en:

https://acontracorriente.chass.ncsu.edu/index.php/acontracorriente/article/ view/1912/3277 Acceso en: 28 jun. 2019)

DE MAURO RUCOVSKY, Martín. "Taedium Vitae: Precarity and affects in porteña night". En E-Scrita Revista do Curso de Letras da UNIABEU Nilópolis, v.10, n. 1, janeiro-abril, 2019b. Disponible en: https://revista.uniabeu.edu.br/index.php/RE/article/view/3554/pdf Accesso en 28 jun. 2019.

FLATLEY, Jonathan. Affective Mapping. Melancholia and the politics of modernism. Cambridge: Harvard University press, 2008

GARCÍA, Esteban Andrés. Percepción y lectura en la filosofía de Simone Weil. Buenos Aires: edit. Teseo, 2015.

MACÓN, Cecilia; SOLANA, Mariela. Pretérito indefinido. Afectos y emociones en las aproximaciones al pasado. Buenos Aires: edit. Título, 2015.

MARX, Karl. El capital. Tomo I. Edición en Español de 1959. Reimpresión de 1995. México:Fondo de cultura Económica, 1995.

MARX, Karl. "Fragmento sobre las máquinas". In: Grundrisse. Lineamientos fundamentales para la crítica de la economía política 1857-1858. Traducción: Wenceslao Roces. México: Fondo de cultura Económica, 1985.

MASSUMI, Brian. Parables of the Virtual. Durham, NC: Duke University Press, 2002.

MCLELLAN, David . Simone Weil. Utopian Pessimist. Londres: Macmillan, 1989.

MOSCARDI, Matías. La rosca profunda. Córdoba: Prebanda ediciones, 2018.

MUÑOZ, José Esteban. Cruising Utopia. The Then and There of Queer Futurity. NY: New York University, 1999. Versión en castellano: Utopía queer. El entonces y alli de la futuridad antinormativa. Buenos Aires: Caja Negra, 2020.

PÉREZ OROZCO, Amaia. Subversión feminista de la economía. Madrid: Traficante de 
sueños, 2014.

PETREMENT, Simone. La Vie de Simone Weil. París:Fayard, 1973. Versión castellana Vida de Simone Weil. Madrid: Trotta, 1997.

RAUNING, Gerard. Mil máquinas. Breve filosofía de las máquinas como movimiento social. Madrid: Traficante de sueños, 2008.

SEDGWICK, Eve Kosofsky. Touching feeling. Affect, Pedagogy, Performativity. Durham: Duke, 2003.

SPIVAK, Gayatri Chakravorty. ¿Pueden hablar los subalternos?. Traducción de José Amícola y Marcelo Topuzian. Buenos Aires: Cuenco de plata, 2011. Disponible en: http://www.macba.cat/ uploads/20170111/spivak pueden hablar_los subalternos.1.pdf Acceso en: 28 jun. 2019.

TOMMASI, Wanda. "Cosmos: la experiencia del cuerpo femenino en Simone Weil". DUODA Revista d'Estudis Feministes. n. 5, 1993. Traducci6n de Maria-Milagros Rivera. Disponible en: https://www.raco.cat/index.php/DUODA/article/viewFile/59934/89265 Acceso en: 28 jun. 2019.

WEIL, Simone. La Condition Ouvrière. Paris: Les Éditions Gallimard, 1951.

WEIL, Simone. La condición obrera. Trad. Antonio Jutglar Barcelona: Ediciones Nova Terra, 1962.

WEIL, Simone. La condición obrera. Trad. Ariel Dilon; José Herrera; Antonio Jutglar. Buenos Aires: Cuenco del plata, 2010.

Submissão: 02/05/2020

Aceite: $18 / 09 / 2020$

https://doi.org/10.5007/2176-8552.2021.e85251

Esta obra foi licenciada com uma Licença Creative Commons Atribuição-NãoComercial 4.0

Internacional. 